\title{
Intermediating Adverse Selection ${ }^{1}$
}

\author{
Vincent Glode \\ vglode@wharton.upenn.edu \\ and \\ Christian Opp \\ opp@wharton.upenn.edu \\ Wharton School \\ University of Pennsylvania
}

January 27, 2013

${ }^{1}$ We would like to thank Franklin Allen, Itay Goldstein, and Guillermo Ordoñez for helpful comments. 


\section{Intermediating Adverse Selection}

We propose a parsimonious model of over-the-counter trading under asymmetric information to study the presence of intermediary chains that stand between well informed parties and uninformed market participants. Multiple moderately informed intermediaries can fulfill an important economic role of "smoothing" adverse selection. Informed market participants may prefer to trade through these intermediary chains as they improve trade efficiency but also reduce the surplus accruing to uninformed traders. Our model makes novel predictions about optimal network formation when adverse selection problems impede the efficiency of trade.

Keywords: Intermediation, Trading Networks, Adverse Selection, Asymmetric Information JEL Codes: G20, D82, D85 